\title{
THE SENATE 2007: BLOCK VOTING IN OPERATION
}

\author{
by Jarosław Flis
}

Elections to the Senate are rarely a topic of deep analysis by media or researchers. The Upper House of the Parliament is not a place where key political decisions are made. The Government, which is appointed by the majority of the Lower House, the Sejm, is the center of Polish political life. Experience show that the political situation in the Senate is much more stable than in the Sejm. From 1997, parties which won elections to the Sejm always had a majority in the Senate, although none of these parties had an independent majority in the Sejm. The 2007 elections crown this trend - only one mandate in the Senate was given to a candidate who did not come from the winning party or any main opposition parties. Every fifth mandate in the Lower House was given to smaller parties. The purpose of this analysis is to find an answer to the question on what leads to such results.

\section{SENATE ELECTIONS}

It is worts beginning from the issue of classifying the Senate ordinacy. Literature review suggests that there is a wide acceptance of describing Polish electoral system as a majority rule which uses not one but two, three, or even four mandate electoral precincts. Dieter Nohlen describes such a system as a sub-type of the classical majority rule system'. However, many researchers point that such a voting system should

1 D. Nohlen, Prawo wyborcze i system partyjny, Scholar, Warszawa 2004, p. 165. 
rather be referred to as "block voting," which explicitly distinguishes it from other type of majority rule voting².

Block voting which is applied in Poland during Senate elections is rarely seen outside Poland. Today, only such countries as Kuweit, Laos, Liban or Syria use a similar system. It was also used in parliamentary elections in Thailand and the Philippines until 1997 when it was modified due to the results it had brought. ${ }^{3}$

Jack Haman classified block voting to quasi-proportional formulas and not majority rule formulas. ${ }^{4}$ This term was used to describe a phenomenon of electing one candidate from a list of many candidates. At the same time, Haman points out that block voting is closer to a first-past-the-post method than a proportional method.

This observation is important mainly because quite often in the debate over the ongoing modifications of the Polish political system the Senate elections are used as a positive example which gives a clearly defined majority but also as a negative example of how, despite the election results, party connections influence the final outcome. Some analysts regard Senate elections as a an example of a system which allows independent candidates to obtain a mandate. Public debates frequently point out to senator Henryk Stokłosa, who was a Senator for many years and who got arrested many years after his mandate expired. Based on this example accusations are made that a majority rule electoral system can lead to a dominance of such candidates.

International Institute, IDEA, in its handbook, Electoral System Design, pointed out to several weaknesses of such a system; political defragmentation, rivalry between candidates from the same political party, and lack of proportional method. ${ }^{5}$ The strongest point of such a system, according to the same handbook, is an opportunity to vote for particular candidates. Also, the block system awards those parties that reveal greatest internal cohesion and good organization.

If we assume that the electorate of political parties is fully loyal and disciplined, we can presuppose that the results in block voting will be the same as results if the first-past-the-post, meaning the winner takes it all, formula was used.

On the national scale, the disproportion of block voting may be higher than in the case of one mandate. ${ }^{6}$ This could happen because larger precincts can even out geographical differences in support towards a given party. Haman, however, points out that in some situation such a voting system will allow a representative of a minor-

2 A. Reynolds, B. Reilly, A. Ellis, Electoral System Design, IDEA, Sztokholm, 2005 p. 44.

3 Ibidem.

${ }^{4}$ J. Haman, Demokracja, Decyzje, Wybory, Scholar, Warszawa 2003, pp. 166-168.

5 A. Reynolds, B. Reilly, A. Ellis, Electoral System..., op.cit.

${ }^{6}$ P. Norris, Electoral Engineering, Cambridge University Press, Cambridge 2004, p. 48. 
ity to obtain a mandate. This happens when the electorate is not loyal to its party and some voters are willing to divide their votes. Secondly, block voting enables a creation of informal coalitions of smaller parties. Each party nominates one candidate and officially agree to transfer votes. In such a situation smaller parties have a chance to win mandates. Haman analyzed election results from 2001. He points out that although the - SLD obtained more mandates than other parties it did not win in all precincts where it had an absolute majority. On the other hand, the Alliance obtained mandates in those precincts where Block Senat 2001 (need to explain the name) lost mandates due to weaker discipline. Herman also points out that smaller parties, such as PSL (Polish Peasant Party) Self-Defence, or the League of Polish Families, managed to keep a few mandates each despite the fact that none of them had a dominant position in any precincts. Haman points out that in the block voting system factors such as organizational skills, loyalty, disciplined voters, and finally proper strategy in selecting and nominating candidates, are very important and can influence the elections' results. A similar example is given by - Cox who describes the consequences of dividing votes in the $19^{\text {th }}$ century England when many electoral precincts would chose two members of the House of Commons. Then, as a result of dividing votes between candidates from different parties, it was possible that a party which dominated in a given precinct would not obtain two mandates but one. The second mandate was given to the opposition, if it only nominated one candidate.

\section{USING VOTES}

The fact that everybody has two, three or four votes, does not mean they need to use them. The National Electoral Committee does not gather statistical data on how many votes are made by individual voters. If a voter in a four-mandate precinct chose only one candidate his vote is treated the same way as the one of a voter who chose four candidates. Nonetheless, such data can be obtained when we compare the number of votes made for all Senate candidates with the number of votes which were made in a given precinct. ${ }^{8}$

When we look at this problem at the national scale we notice that only 76 per cent of the allowed votes were actually used. It means that ever voter did not use at least one of the votes it was allowed. Using allowed votes depends on the precinct size. In twomandate precincts the level of using allowed votes was estimated at 79 per cent (21 per

\footnotetext{
7 G.W. Cox, Making Votes Count, Cambridge University Press, Cambridge 1997, p. 43.
}

8 All estimations based on page strony wybory2007.pkw.gov.pl 
cent was not used at all). It means that, for example, two out of every five voters chose only one candidate and three chose two candidates. In the case of three mandate precincts 72.5 per cent of allowed votes were not used. This could be explained by a number of configurations - different electoral behaviour (or different behaviour of voters) can lead to different results. It can turn out, for example, that only one out of five voters chose three candidates whereas the remaining four chose two candidates. Such result can be also obtained when three voters out of five will use all votes allowed but two will choose one candidate. There are only two four precincts - in both cases voters used 74 per cent of allowed votes. Here the number of possible configurations of behaviours leading to such a result is even larger. Basically, such an effect can be achieved when out of every voters two used four votes each, and the third voter used only one vote.

What can lead to such a phenomenon - why voters chose fewer candidates than they are allowed? Why do they give up their right? Two hypotheses are possible here. One of the hypotheses states: such electoral behaviour can be explained by the complexity of the system and because in other elections, for example in council elections or parliamentary elections (?) (basiacally in all other elections) they have only one voice. They transfer the same mechanism, the same logic, to block voting without noticing a difference in the mechanism itself. In fact, such voting is a result of lack of awareness of how a given voting system works and what are the voter's rights in this system.

A completely different explanation is also possible. If, during the elections, which are run in accordance with block voting, a voter who chooses only one candidate, whose victory is in his interest, then the only logical (good) strategy is to choose only one candidate and give up voting for others. Each vote given to other candidates increases the probability that they will beat that only candidate. This means, if a voter has only one preference, and the other candidates are indifferent to him, in such a situation the number of given votes is limited. There are two explanations to such a situation: either a very low level of voters' competence or a very high level of voters' competence. A competence, which notices very subtle, and at first sight invisible, voting mechanisms which characterize (accompany) block voting. Indirect explainantions are also possible - the voter notices only a limited number of candidates whom he/she trusts. The voter does not trust the remaining candidates and does not give them his/her vote without taking into consideration negative consequences of not voting for other candidates. In this way, the voter gives up the ability to show his/her preference by showing that equal negative attitude towards all remaining candidates. The phenomenon of a limited use of votes inevitably influences the results - this is another factor considered in the analysis of support for individual candidates. 


\section{MAJORITY RULE IN ACTION}

Only six out of one hundred elected senators received support of the absolute majority of the voters. Figure 1 illustrates the distribution of support towards candidates to the Senate who won the elections - from the ones with the largest support to the ones with the least support. A candidate which received the largest number of votes gained support of 63 per cent. Slightly more than 20 per cent of votes allowed a candidate to obtain a mandate, which is regarded as the least support received. Such electoral outcome (result) is very far from the absolute majority and suggests a very large fragmentation of votes in a precinct. Between these two extremes are the results of other winning candidates. While 14 senators received a support in the range of 40 to 50 per cent, majority of winning candidates (51 senators) received a support in the range of 30 to 40 per cent. Voters' support of less than 30 per cent was given to 29 senators. Fragmentation of votes did not take place in all precincts. However, in great majority, meaning in 80 per cent of all precincts, candidates lacked at least 10 percent to receive an absolute majority. An average winning candidate would receive 35 per cent of electoral support.

In some precincts a fiercer competition took place between a smaller number of candidates while in some precincts the number of strong candidates was larger. In effect, 75 per cent of candidates who did not get elected received a larger support than the senator who was elected to the Senate with the lowest support of 20 per cent. The strongest candidate who did not receive a mandate received 32 per cent of votes. Such support, however, was not enough in the precinct in which he run, although in other precincts it would give him a smashing victory.

Rys. 1. Support for senators

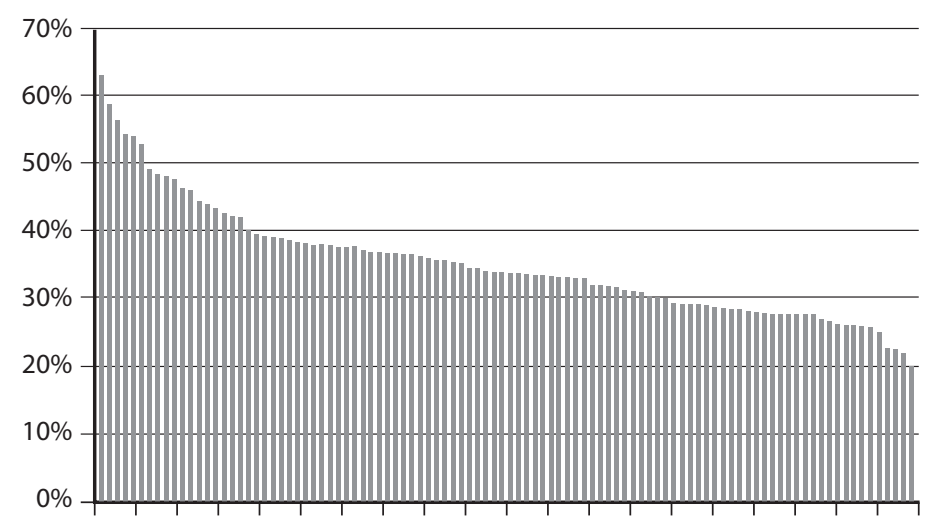

Source: own estimation based on wybory2007.pkw.gov.pl 
One can look at the support which the winning senators receive not from the perspective of the voters but from the perspective of the cast votes keeping in mind that a significant share of voters casts only a part of votes they are allowed. In this way, inevitably, the number of votes for one candidate can be reduced significantly.

In a one-mandate precinct the percent of votes given to all candidates totals to 100. In a multi-mandate precinct, in which voters do not use all votes they are allowed, votes do not total to 100 multiplied by a number of mandates to win. That is why, in these precincts it is much harder to receive a support of more than 50 per cent of voters than in case of one-mandate precinct.

\section{PARTY IDENTIFICATION}

The importance of party identification can be assessed by comparing the results of elections to Sejm and Senate. If the statement about a greater personalization of Senate elections is true, then a significant discrepancy should appear. The first step in the analysis is to compare the number of received votes in both precincts by the candidates from one party. In the case of elections to Sejm it is very simple. These results are available on the website of the National Elections Commission where the total number (or final result) at the national level is provided. In the case of Senate elections to obtain such data requires a detailed calculation of results in all precinct (table 1$)$.

Tab.1. A comparisan of party results in Sejm and Senate elections

\begin{tabular}{|c|c|c|c|}
\hline & \multirow{2}{*}{$\begin{array}{c}\text { Sejm - votes for } \\
\text { lists }\end{array}$} & \multicolumn{2}{|c|}{ Senate } \\
\hline & & $\begin{array}{l}\text { sum of votes for } \\
\text { candidates }\end{array}$ & $\begin{array}{l}\text { average score of } \\
\text { a candidate }\end{array}$ \\
\hline $\mathrm{PO}$ & $41,5 \%$ & $39,1 \%$ & $33,6 \%$ \\
\hline PiS & $32,1 \%$ & $31,4 \%$ & $27,0 \%$ \\
\hline $\mathrm{LiD}$ & $13,2 \%$ & $14,6 \%$ & $15,0 \%$ \\
\hline PSL & $8,9 \%$ & $8,8 \%$ & $14,2 \%$ \\
\hline
\end{tabular}

Source: own estimation based on wybory2007.pkw.gov.pl

In the Sejm elections, the Civic Platform received 41.5 per cent of votes, a total number candidates received in the Senate elections is lower by about 2.5 per cent: 39.1 per cent of all votes received in the Senate elections. Law and Justice received 
32.1 per cent in the Sejm elections and 31.4 per cent in the Senate election, which is less than one percentage point. Liberal and Democrats received 13.2 per cent in the Sejm elections and 14.6 in the Senate elections, about 1.4 percentage points more. In the case of Polish Peasant Party there is the least difference 8.9 per cent to Sejm and 8.8 per cent to Senate. A comparison of these results suggest a very similar tendency in elections to both houses of the Parliament. The difference isnot larger than 2.5 percentage points. Such comparison would suggest that there is a strong correlation between these results. However, a more careful analysis leads to some modification of this thesis.

Another set of data worth analyzing are the votes candidates to Senate received in individual precincts in comparison with the results parties received in elections to Sejm. The candidates of the wining Civic Platform received, on average, 33.6 per cent of votes given in a given precincts, meaning about 7 percent less than what the party received in the Sejm elections. The Law and Justice candidates received, on average, 27 per cent of votes, meaning about 5 per cent less than in Sejm elections. Candidates from LiD received 15 per cent as compared to 13.2 per cent in the elections to Sejm. In the case of the Polish Peasants' Party it was 14.2 per cent versus almost 9 per cent in the Sejm elections. It is apparent that the support for the candidates from the two strongest parties is lower in the elections to Sejm, in the case of LiD the results are very similar, whereas in the case of the Polish Peasant Party the results of the candidates are significantly higher than those in the elections to Sejm. If, after a closer look, the exceptional correlation between the number of votes received by parties in elections to Sejm and Senate is less obvious then a question emerges regarding the correlation between the results of Senate elections with the results from the elections to Sejm. This would be another measure of voters' party loyalty. The main indicator here is very straightforward. The correlation between the final results that were obtained by the candidates in Senate elections and the support that their party received in the same precinct was $0,9^{9}$. This is a very strong correlation - it would suggest that the support for a candidate in the elections to the Senate is in almost 90 per cent explained by a general support for his/her party in a given precinct. However, figure 2 suggests that there is no straight relationship between a support for a given party and support for its candidate in the Senate elections. The candidates of a party with a much smaller support usually get a better result than the party itself. However, in a great majority of cases when a party received support of 30 per cent or more, support for candidates to Senate was much smaller than the party's results in Sejm elections.

\footnotetext{
9 Exactly 0,89888.
} 
Rys. 2. Support for a Senate candidate and support for the party

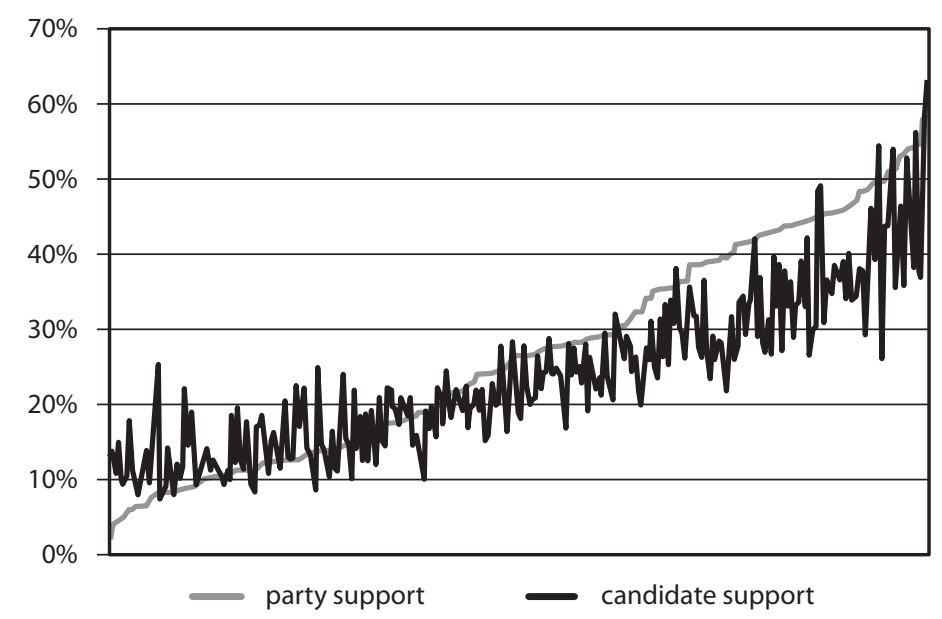

Source: own estimation based on wybory2007.pkw.gov.pl

It is worth to analyzing this support with a reference to particular parties. Such high correlation when controlled for which party candidates come from, decreases significantly. The biggest fall takes place in the case of the Civic Platform. In the case of its candidates the correlation reaches 0.83 , meaning not much less than a correlation for all candidates. In the case of Law and Justice such correlation reaches 0.77 , meaning that the results achieved by the candidates of this party will depend on the actual results of this party. A much smaller coefficient is in the case of candidates from smaller parties. In the case of $\mathrm{LiD}$ it is 0.53 while in the case of the Polish Peasants' Party is 0.31 . These are very strong correlations, however not as overbearing as it is in the case of a general coefficient. It seems that this direct high correlation is, in part, a result of a defragmentation of results of a given party, and, in part, it is a correlation with their general size and not a particular result. If we create a variable which would assign to each party a number which represents its place in the elections to Sejm (from 1 to 4 ) then support for particular candidates to the Senate is correlated with a corresponding value of 0.73 . However, there is a clear regularity which passes the simple correlation in the relation between the candidate's results in the Senate elections and support for his party in a given precinct. The answer to this question will be sought in the remaining part of this analysis.

The next step in the analysis is to compare differences between the results obtained by the Senate candidates and results their parties received in the precincts (table 2). This difference depends on the party in question. The candidates of the Civic Platform, the winning party in the Sejm elections but also a party which received the biggest number of mandates in the Senate, received, on average, about 7 per cent 
points less than this party received in the Sejm elections in the same precincts. This is a decline in support calculated as a percentage of the number of votes received. When we compare it with the results that the party received in a given precinct than it means that, on average, 18 per cent of the party's voters did not vote for its party's candidates to the Senate. A similar result can be obtained for Law and Justice. Candidates to the Senate from this party received, on average 6 percentage pointsless than their party received in the precincts in which they run. When the data is compared to the results obtained by Law and Justice it turns out that 17 per cent of the party's voters did not vote for its candidates in the Senate elections. Such a comparison means that there is a small flow, a small degree of disloyalty, which is understood as voting for different candidates in Sejm and Senate elections. This disloyalty could be larger if, for example, a number of voters voting for the Civic Platform to Sejm would vote for Law and Justice to the Senate and the other way round: when Law and Justice voters to Sejm would vote for the Civic Platform to the Senate. However, this disloyalty is not smaller than the values presented. The case is completely different in the case of smaller parties. In the Senate elections, candidates from $\mathrm{LiD}$ received, on average, 2 percentage points more than their party in the Sejm elections, which when compared to the general support for LiD means that their candidates to Senate got one fifth of votes more. In the case of the Polish Peasant Party these percentage points are even higher. Their candidates received, on average, 3 percentage points more, meaning half more votes in comparison to the support that their party received from voters.

Tab. 2. A comparison of party candidates' results in election for the Sejm and the Senate

\begin{tabular}{|l|c|c|}
\hline \multirow{2}{*}{} & \multicolumn{2}{|c|}{$\begin{array}{c}\text { an avwerage difference between a candidate's support } \\
\text { for the Sejm and his/her support for the Senate }\end{array}$} \\
\cline { 2 - 3 } & absolute & simple \\
\hline PO & $-7 \%$ & $-18 \%$ \\
\hline PiS & $-6 \%$ & $-17 \%$ \\
\hline LiD & $2 \%$ & $20 \%$ \\
\hline PSL & $3 \%$ & $52 \%$ \\
\hline
\end{tabular}

Source: own estimation based on wybory2007.pkw.gov.pl

In effect, of course these are average values, however, in the case of the Civic Platform 12 per cent of its candidates received a larger support than their party in the Sejm elections and yet 88 per cent of the candidates received a smaller support than their party. In the case of Law and Justice 11 per cent of candidates received 
a larger support than their party and 89 per cent received a smaller support than their party. An almost opposite trend characterized LiD and the Polish Peasants' Party where 73 and 70 per cent of candidates respectively had a larger support than their party in the Sejm elections and 27 and 30 per cent of candidates, respectively, had a smaller support.

\section{REMAINING CANDIDATES}

The hypothesis which should be considered is the influence of independent candidates. The public as well as the researchers consider majority voting system to be more personalized and giving a better chance to non-party candidates. The results of the 2007 Senate race do not support this hypothesis. Candidates from other parties than the four winning ones received 6.1 per cent of the winning votes. A little more than half of these votes got candidates from parties which already had a seat in the Sejm in the previous term. These were candidates from Self-Defence and League of Polish Families. In the case of the latter, the name of the party was changed into the League of Polish Right (in Polish language the abbreviation remained the same - LPR), which was created by the League of Polish Families, the Right of the Polish Republic, and the Union of Real Politics. In the Senate race, however, the candidates of these three parties run under three different aegis. Only Marek Jurek from the Right of the Polish Republic received a 19 per cent support in the precinct of Piotrków Trybunalski. However, it was not enough to give him a seat in the Parliament.

The remaining candidates which were not affiliated with any of the parties already in the Parliament received less than 3 per cent of the votes at the national level. Nonetheless, one of these candidates received a vote. It was Włodzimierz Cimoszewicz who ran in the precinct of Białystok. He ran as an independent candidate although he was known to the public as a long member of the Democratic Left Alliance (which in the last elections was part of the LiD coalition), a former Prime Minister, Minister of Foreign Affairs, and Speaker of the House. This case will be discussed in the later part of the analysis. Jaroslaw Lasecki in the Czestochowa precinct received 25 per cent of the votes, a number too small to give him a seat. He run as an independent candidate and a winner in previous elections. He ran as an independent candidate who, nonetheless, was involved in the parliamentary club of Law and Justice and who left the club a month before the elections. ${ }^{10}$ Nonetheless, the 6.1 per cent of votes received by the candidates who ran from other than the four

${ }^{10}$ Based on www.senat.gov.pl 
winning parties is a result only slightly higher than the one received by parties which did not win any seats in the Parliament. All these parties together received 4.3 per cent of the votes. Less then 3 per cent received by candidates without any party identification proves that these candidates do not play a significant role in the Senate race, especially since from these candidates the most successful ones were the ones who had an earlier party affiliation.

\section{ORDER ON THE LIST}

The next problem is the importance of the position on the voting list and its relation to the outcome of the elections. The candidates to the Senate are placed on the list in the alphabetical order. This fact appears to have a significant importance to the outcome of the elections. In the case of the candidates which are lower on the list, who are the subsequent candidates of the same party, there is a significant decline in the number of votes received. An average candidate of the Civic Platform whose name was in the second position on the list, received 8 per cent fewer votes than his party colleague whose name was placed on a higher position. In the case of Law and Justice, such a loss reached, on average, 7 per cent of the votes. In the case of candidates from $\mathrm{LiD}$ whose names were further down on the list was 11 per cent, however, it was the biggest in the case of the Polish Peasants' Party - 19 per cent of the votes. For all candidates from the four main parties such loss was, on average 10 per cent of votes.

Where does this difference come from? It seems this it is a result of dividing votes as well limited voting. It seems that a part of voters who are characterized by a high party loyalty, is indifferent towards which candidate they vote for. If they make one vote, they usually vote for the first candidate on this list. If they divide their votes towards candidates from different parties then it is usually designated towards the first candidate on the list.

It does not mean that the results are straightforward. Of course, there are candidates which are on further places and received significantly better results than their colleagues whose names were placed higher on the list. This referred to people with a much more defined public image, who, before, held public offices and were often present in the media. The largest difference is between the first and the second candidate, especially in the case of the Civic Platform and LiD. However, in the case of the Law and Justice and the Polish Peasants' Party the difference between the first and the second candidate and the second and the third were very similar.

Such a phenomenon suggests that from the hypotheses explaining a smaller number of votes than a voter is allowed, a more probable is the one which explains 
such voter behaviour by lack of awareness of law that allows a larger number of votes than a voter's decision to vote only for a preferred candidate. It can be assumed that if the application of limited voting to practice was a conscious and rational choice of a strategy which is based on not voting for impartial candidates, then there would be no clear correlation between the number of votes and their appearance on the list. An alternative hypothesis which suggests that candidates who are better assessed by the voters are characterized by a last name which starts with an earlier letter of the alphabet doest not sound convincing. Such a correlation rather suggests that dividing votes among different candidates is more a result of sophisticated political views and voter's position on the ideological scale of different political parties more than issues other. This clear correlation between the position on the voting list suggests that voters who vote in such a way are not interested in the candidates and vote for parties. By doing so they chose the first candidate they notice on the list. However, in the majority of cases candidates whose names were in the later position on the list received fewer votes than the proceeding candidate. It indicates that there is a significant group of voters who still prefer to chose a candidate they know regardless of his/her party preferences. This is a subject for further analyses. It would be particularly useful to test the phenomenon of the incumbent advantage ${ }^{11}$.

\section{PARTY STRATEGIES}

While developing Jack Haman's hypothesis that in the case of block voting a significant importance is given to the choice of the strategy, meaning the choice of candidates, who are chosen by the party in a given precinct, it is worth analyzing how this problem has been solved by the four main parties in the 2007 Senate race. Evidently aware of this problem political parties use two different strategies. An optimistic strategy is used when a party prepares a voting list where the number of candidates equals to the number of mandates in a given precinct. A pessimistic strategy means that a party nominates fewer candidates than there are seats to be won. None of the parties used an optimistic strategy in all precincts, although all parties used it in a considerable number of precincts. Here there is a big difference between large parties such as the Civic Platform and Law and Justice and smaller parties: LiD and the Polish Peasants' Party. First of all, large parties nominate a larger number of candidates. The Civic Platform provided 15 candidates while Law and

11 P.R. Abramson, J.H. Aldrich, D.W. Rohde, Change and Continuity in the 2000 and 2002 Election, CQ Press, Washington 2004, p. 200. 
Justice provided 13 candidates. LiD provided 29 candidates and the Polish Peasants' Party 48 mandates. At the precinct level, the Civic Platform and Law and Justice, regardless of the precinct size, provided at most one candidate, while LiD and the Polish Peasants' Party did not nominate anybody in some of the precincts. In the case of LiD, the party did not nominate any candidate in the Poznan precinct, while the Polish Peasants' Party did not nominate any candidates in Łódź, Poznań, Nowy Sącz, Katowice i Legnica. In six of the three-mandate precincts the Polish Peasants' Party nominated only one candidate. Similarly, $\mathrm{LiD}$ nominated only one candidate in four of the three-mandate precincts. In terms of two four-mandate precincts, Krakow and Warsaw, the Polish Peasants' Party nominated only one candidate in each of these precincts. LiD nominated all four candidates in Warsaw but only two in Krakow. The Civic Platform and Law and Justice behaved in a similar way: nominated four candidates in Krakow and one fewer in Warsaw.

Even the motivation behind the adoption of the pessimistic strategy is to counteract the effects of limited voting and division of votes, such behaviours do not refer to all voters. Loyal and conscious voters can, in such a situation, give up their right to make all votes they are allowed and by doing so they will lower the national level of votes usage. To test this phenomenon, correlations between the number of missing candidates and the amount of used votes in a given precinct was established.

Generally speaking, an incomplete list of candidates nominated by the party leads to a smaller number of used votes. The correlation between used votes in particular precincts and the number of missing candidates in four main parties is 0.57. Each additional missing candidate lowers down the number of used votes in a given precinct.

The next problem related to optimistic and pessimistic strategies is the question on what basis these decisions are made. To answer this question a correlation between the number of candidates that the party nominated in a given precinct and the difference between the support towards this party and support towards the winning candidate in the precinct was measured. If the party won in a precinct than the difference was 0 . Such correlation was measured for four parties. First, the choice of strategy was compared to the election results from the 2005 Sejm race. Second, a comparison was made with the results of 2007 elections as a parameter which hypothetically parties could consider as a prediction of the shape of election results. In the case of the Civic Platform the correlation between the number of mandates and the difference in 2005 was 0.3 while in the case of the Law and Justice it was 0.59 . It is evident that Law and Justice associated the choice of the pessimistic strategy with the difference between the results from different precincts. In precincts where the difference was to the advantage to the Civic Platform, then the party would more frequently choose the pessimistic strategy. A similar difference is in the case of the 
2007 race. Here for the Civic Platform the coefficient was 0.26 while for Law and Justice it was 0.56 . Despite similar values, it is worth underlining that the coefficients for 2005 are, in both cases, higher. It suggests that while designing a strategy parties referred more to election results from 2005 than to public opinion polls. In the case of parties who completely lost the elections, that is $\mathrm{LiD}$ and the Polish Peasants' Party, these coefficients amount to 0.35 for LiD in 2005 and 0.59 for the Polish Peasants' Party. Similarly to Law and Justice, the Polish Peasants' Party took the 2005 results into consideration. LiD took the 2005 results only slightly more seriously than the Civic Platform. For these two parties, in 2007, these coefficients are 0.27 and 0.56 respectively. Therefore, in this case we have a similar phenomenon to that of larger parties. If any indicators were taken into consideration, these were usually the results from 2005 than any prognoses for 2007. It appears that parties made rational choice in reference to limiting the number of candidates they nominated. High indicators of the correlation suggest an awareness of the problem which is generated by the current system. Nonetheless, although in many cases the 2005 elections conditioned the adopted strategy this subordination to previous results was not full. In each party there were cases where a different strategy was chosen than the previous results would indicate.

\section{POLITICAL RESULTS OF A STRATEGY}

Adopting pessimistic strategy had to limit the diffusion of votes which is a result of limited voting as well as dividing votes. In order to assess the effectiveness of this strategy averages of the support towards candidates to the Senate from different parties and the strategy adopted by parties were compiled (table 3). In order to eliminate the influence of the general support towards a party in a precinct the calculation was based on the difference between the results obtained by a candidate and the results of his party in the Sejm elections in the same precinct. Which means, as it was argued above, this parameter has a positive value in the case of $\mathrm{LiD}$ and the Polish Peasants' Party but negative in the case of the Civic Platform and the Law and Justice.

In the first place, I discuss the influence of a strategy on the support towards candidates of a party which adopted such a strategy (bolded values). Adoption of a pessimistic strategy was related to an increase in support (calculated in such a way) in all parties. Support for the Civic Platform candidate increased, on average, by 3.3 per cent when the pessimistic strategy was used. In the case of Law and Justice such difference was 6.3 per cent, for LiD 4.3 per cent, and for the Polish Peasants' Party it was 6.1 per cent. For all candidates together, when considering the relations 
between the party's results and the results achieved by its candidates in the Senate race, an increase in support when a party used a pessimistic strategy was 4.5 per cent of votes.

Tab. 3. The results of pessimistic and optimistic strategies in the Senate elections

\begin{tabular}{|l|c|l|c|c|c|}
\hline & \multicolumn{2}{|c|}{$\begin{array}{c}\text { anaverage result of a Senate candidate compared } \\
\text { with the results of the Sejm elections }\end{array}$} & \multirow{2}{*}{ no. of cases } \\
\cline { 1 - 4 } Strategy & PO & PiS & LiD & PSL & \\
\hline PO - optimistic & $-8.5 \%$ & $-5.2 \%$ & $1.3 \%$ & $2.8 \%$ & 26 \\
\hline PO - pessimistic & $-5.2 \%$ & $-8.8 \%$ & $2.8 \%$ & $3.3 \%$ & 15 \\
\hline PiS - optimistic & $-6.8 \%$ & $-7.5 \%$ & $1.8 \%$ & $1.8 \%$ & 28 \\
\hline PiS - pessimistic & $-8.8 \%$ & $-1.2 \%$ & $2.1 \%$ & $6.2 \%$ & 13 \\
\hline LiD - optimistic & $-8.4 \%$ & $-5.9 \%$ & $0.2 \%$ & $0.7 \%$ & 15 \\
\hline LiD - pessimistic & $-6.8 \%$ & $-6.2 \%$ & $4.5 \%$ & $4.7 \%$ & 26 \\
\hline PSL - optimistic & $-7.3 \%$ & $-8.4 \%$ & $1.1 \%$ & $-0.5 \%$ & 9 \\
\hline PSL - pessimistic & $-7.5 \%$ & $-5.4 \%$ & $2.2 \%$ & $5.6 \%$ & 32 \\
\hline
\end{tabular}

Source: own estimation based on wybory2007.pkw.gov.pl

Visibly, an adoption of a pessimistic strategy is a rational behaviour for political parties which are aware that they will not receive the highest support in a precinct. Nonetheless, it has its disadvantages. Some of the voters when faced by an incomplete list of the candidates from a party they support, may, in such a situation, give their votes to candidates from a different party. What is the relationship between a strategy of one party and support towards candidates of another party? The answer is not easy since the adoption of this strategy is based on the parties exit situation, that is the 2005 results. Nonetheless, direct correlation between strategies used by parties are very weak - the value of the coefficient does not get higher than 0.25 . The strategies themselves can be then regarded as independent variables. Majority of relations between the support for candidates of one party and a strategy of a different party can be explained by the positions parties take in a two-dimensional scheme of ideological divisions ${ }^{12}$ and the flow of votes between parties. The biggest difference is noticed in the case of the Polish Peasants' Party. Support for this party increases, on average, by 4 percentage points when LiD adopts the pessimistic strategy. This support

12 R. Markowski, System partyjny, [in:] Demokracja w Polsce 2005-2007, L. KolarskaBobińska, J. Kucharczyk, J. Zbieranek (eds.), Instytut Sprzaw Publicznych, Warszawa 2007, p. 168. 
increases even more, by 4.4 percentage points, when a pessimistic strategy is adopted by Law and Justice. Although it may appear paradoxical as the Law and Justice (Flis used PSL - probably a mistake but need to ask) and LiD are placed on two extreme ends of the main axis of political differences ${ }^{13}$, nonetheless this central position is to the advantage of the Polish Peasants' Party ${ }^{14}$. However, in the case of the Civic Platform the pessimistic strategy of this party is related to only a small gain (lead) of the candidates of the Polish Peasants' Party (0.5\%).

Even if some of these values are a result of apparent dependencies, their totaleffect is hard to ignore - in precincts where all parties used pessimistic strategies (Gdynia and Opole), support for the Polish Peasants' Party was by 8 percentage points higher (after considering difference of the support in the Sejm race) than in the precincts where all parties used optimistic strategies (Piotrków Trybunalski and Toruń).

While the Polish Peasants' Party appear as the party of the second choice for some of the Law and Justice and LiD voters, the latter seem to be less of a beneficiary of the adoption of pessimistic strategies by other parties. The difference in support for $\mathrm{LiD}$ candidates when a pessimistic strategy is adopted is the biggest for the Civic Platform. It is only 1.5 per cent of votes. In the case of the Polish Peasants' Party it is 1.1 per cent. It does not seem that an incomplete list of candidates used by the Law and Justice would increase support for LiD. The difference here is only 0.3 per cent and can be a result of other variables. The same difference, although a decreasing support, is noticed in the support for Law and Justice candidate depending on the strategy adopted by LiD. A pessimistic strategy adopted by LiD decreases the support for Law and Justice. In the case of the Polish Peasants' Party there is a visible difference. In the precincts where the party adopted a pessimistic strategy, the candidates of Law and Justice receive, on average, 3 per cent more votes. It is more difficult, however, to interpret the fact that in the precincts where the Civic Platform chose a pessimistic strategy, the candidates from Law and Justice received a smaller support (a similar situation takes place in the case of support for the Civic Platform in precincts where Law and Justice chose a pessimistic strategy). This relation has probably some apparent dependency a derivative of the overall arrangement of strategies of other parties. This problem can be explained by a analysis path described observations can become a basis for a model (troche przeredagowac)

In the end, support for the winning party, the Civic Platform, is to the lowest degree dependent on strategies adopted by other parties. In the case of $\mathrm{LiD}$ and the Polish Peasants' Party there are small differences. A pessimistic strategy adopted by

13 See: M. Grabowska, Podział postkomunistyczny, Scholar, Warszawa 2004.

14 J. Flis, Blokowanie list i koalicje w sejmikacj wojewódzkich, [in:] A. Wołek, Władza i polityka lokalna, OMP, WSB-NLU, Kraków-Nowy Sącz 2008, p. 20. 
$\mathrm{LiD}$ is related to a 1.5 per cent increase in support for the Civic Platform candidates and a pessimistic strategy of the Polish Peasants' Party with an even smaller difference (0.2 per cent).

Paradoxically, the election results of the Polish Peasants' Party, which created a coalition government with the Civic Platform, is only to a very small degree related to the strategy of the Civic Platform (and reversely) and can count on the support of the electorate of two opposition parties - Law and Justice and LiD - which stand at two extreme ends of the political spectrum.

A detailed analysis of the election results in particular precincts shows that parties made some poor (poor, weak...??) in their choice of election strategy. Two types of mistakes are possible here. First, a party adopts an optimistic strategy in a precinct where a pessimistic strategy would increase its chance to obtain a mandate. Second, a pessimistic strategy is adopted at the moment when an optimistic strategy would increase a chance to win the race. Additionally, in some situations, the election results did not depend only on the strategy adopted by the party but also on the final choice of the strategy adopted by other parties.

In the case of 8 mandates obtained by the Law and Justice there was a chance that the party will loose them to the advantage of the Civil Platform. In the case of four mandates such a situation was highly probable. In the case of four remaining ones, it was less probable. Had a different strategy been adopted, Law and Justice could have won six mandates which otherwise went to the Civic Platform. In four cases, a change in strategy would almost certainly allow Law and Justice to win the race while in the case of two mandates it was less probable, but possible.

LiD candidates, who lost the race, could have won three mandates at the cost of Law and Justice if the strategy was changed. However, it was only possible, in all cases discussed, if the Civic Platform chose a wrong strategy. One of the Polish Peasants' Candidates could have won a race if his party gave up nominating another candidate in his precinct. However, in a few precincts candidates of a smaller party used the pessimistic strategy and lost by a hair's with the candidates of larger parties.

The essence of the less obvious consequences of adopting different strategies by parties is the success of Włodzimierz Cimoszewicz. This success resulted from the fact that in the precinct of Białystok three parties, the Civic Platform, LiD, and the Polish Peasants' Party, chose a pessimistic strategy. Therefore, an independent candidate could be a candidate of a third choice for supporters of all three parties. Together, in the Sejm race, these parties received 56\% of support. Even if one in every three voters gave up his/her right to make a third vote, there are still 38 per cent of votes left. This is exactly the support received by Włodzimierz Cimoszewicz. Without belittling his position in the region, his success would be, by far, less probable in any different system. Another candidate, a former Speaker of the House - Marek Jurek 
- ran in a precinct where all parties used an optimistic strategy and closed for him the door that allowed Włodzimierz Cimoszewicz to enter the Senate.

\section{SUMMARY - A MODEL OF A SENATE VOTING}

The analysis leads to a real model of relations between different phenomena taking place in block voting (figure 3 ). The effects that accompany block voting at the level of voters' behaviour is: first, limited voting, second, division of votes. Limited voting means making less votes than the election law allows while division of votes means lack of party loyalty and voting for candidates from different political parties. Each of these mechanisms, which from the perspective of a political party is a found phenommenon leads to a dilemma: should a pessimistic strategy be used? Adopting such a strategy is very rational. It prevents a diffusion in votes and losing mandates to the advantage of parties whose results are only slightly smaller or who themselves adopted a pessimistic strategy.

Rys. 3. A Model of Dilemmas in Block Voting

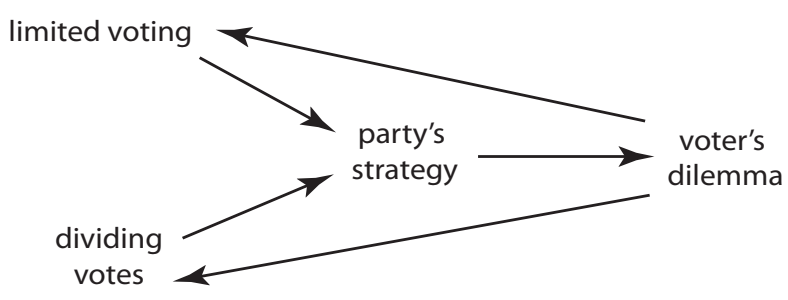

Source: own work.

A decision to limit the number of candidates leads to dilemmas among loyal and political savvy voters. While finding a smaller number of candidates on the list than his/her votes allow, a voter can adopt one of two strategies. The first one is limited voting, meaning not using all his/her votes by not voting for candidates from other parties. The second one is division of votes and voting for a candidate from another party. In this context it becomes visible that an adoption of a pessimistic strategy by a political party enforces two phenomena which were the basis to choose such a strategy. This leads to a feedback since the more voters use limited voting or divide their votes, the more important it becomes for the party to choose a strategy. That is why when a pessimistic strategy is used in a precinct where an optimistic strategy could have been used, then a party increases a chance of the competing party to win additional votes. 
An analysis of the Senate race results does not allow for a statement that in these elections the so-called psychological effect, meaning a need to vote for a wining candidate, the one who has the highest chance to win the mandate, plays a role. The fact that the LiD and Polish Peasants' Party candidates received a larger support than their parties did in the Sejm race allows a statement that voters were more prone to candidates of these two parties than they would have been in a proportional voting system. Such a situation could be influenced by the fact that voters these races as less important in the fight for the executive power, which, as Cox argues, is one of the key impulses in the direction of the two-party system. ${ }^{15}$ In Poland, such an impulse is visible in the Sejm race but not in the Senate race. Second, an opportunity to make more votes encourages voters to divide them in order to express their indecisiveness or lack of straight party identification. Third, this is a result of dilemmas faced by voters of larger parties in the face of adopting by parties pessimistic strategies.

An attempt to guess if results were the same if the Senate race would decide on who will govern is unfortunately a pure speculation. Nonetheless, in the block election system, voters do not follow the direction described as the Duveger's law ${ }^{16}$. Conclusions of this analysis partially confirm the findings of Jack Haman that Poland has as quasi-proportional electoral system. Candidates from weaker parties have a chance to get into the Parliament in precincts where their party is dominated by other parties.

Unquestionably, with the current shape of the party system and current divisions on the political scene, similarly as it was in the previous elections, the election system guarantees a straight (?) majority in this race. However, this is a result of purely mathematical calculations and not a psychological need recorded among voters to support candidates who have a higher chance to win.

15 G.W. Cox, Making Votes Count..., op.cit., pp. 190-192

16 Duverger M. Political Parties, 1954, from: Making Votes Count..., op.cit. 